\title{
Booknotes Notes de lecture
}

Manuela Morresi. Jacopo Sansovino. Milan: Electa, 2000. Pp. 526.

It is hard to imagine a more ubiquitous and prominent Renaissance artistic figure than Jacopo Sansovino. Working in both sculpture and architecture, he received major commissions in the three main artistic centres, Florence, Rome, and Venice, which is more than can be said for Raphael, Michelangelo, or Leonardo. This magnificent book, concentrating on Sansovino's architecture, complements Bruce Boucher's 1991 monograph on Sansovino the sculptor and offers a timely new assessment twenty-five years after Deborah Howard's 1975 book on Sansovino as architect. Whereas Howard's book was focused on the Venetian period, Morresi's offers a complete overview of the artist's career, informed by the enormous scholarly output on Renaissance architecture that has gathered in the last twenty years, especially in relation to the major exhibitions on Raphael, Francesco di Giorgio, Leonardo, Giulio Romano, and Michelangelo.

The book begins, somewhat unusually, with a catalogue raisonné and offers at the end a discursive treatment of Sansovino's career, separated into three sections - on Florence, Rome, and Venice. As some of the catalogue entries are substantial chapters in themselves, offering tightly knit and well informed arguments rife with useful bibliographical references, discussions of the projects are at times split between the essay and entry, and navigation is made more difficult by Electa's idiosyncratic policy of not introducing figure numbers in the text, leaving the reader to hunt down drawings by inventory number throughout the book. These choices of formatting and, ultimately of genre, compromise the force of the book, which is full of ambitious and challenging interpretations aimed at bringing out the social and ideological implications of an increasingly rich and self-conscious architectural culture. The book is written for the experts, and one can only hope that the larger lessons will reach a wider audience.

ALEXANDER NAGEL, University of Toronto 